\title{
elyRa
}

\section{Poética y Política sin Mundo}

\section{Antonio Méndez Rubio \\ Universitat de València}

Resumen: La relación entre poética y política se da hoy fracturada por un mundo a su vez fracturado, en crisis. Esta incomunicación entre lo poético y lo político se desplaza a menudo, de una forma sublimada, hacia la relación entre estética y ética. Pero lo más frecuente es que poiesis y politeia estén aprendiendo a subsistir en una soledad que las condena a la esterilidad. En los límites de una subjetividad perforada por nuevas formas de presión, este artículo busca responder a la cuestión: ¿qué opciones quedan para que la creatividad se convierta en una nueva forma de comunicación, de vínculo crítico? A esta pregunta se intenta responder reconsiderando los condicionantes teóricos y pragmáticos de la relación entre poética y política, entre soledad y comunidad.

Palavras Clave: Poética, política, estética, poiesis, politeia, soledad, comunidad

Abstract: The relationship between poetics and politics is fractured due to being in a world equally fractured, in crisis. The resulted split moves poetics and politics towards a so-called (and often sublimated) relationship between ethics and aesthetics. In fact, it seems that poeisis and politeia are learning to survive in a sterile and confine solitude. In the limits of a subjectivity bored by new ways of pressure, this article seeks to answer to this question: what are the options for creativity to become a new manner of communication and, most importantly, a critical link? The attempted answer will consider the current theoretical and practical circumstances of the relationship between poetics and politics, between solitude and community.

Keywords: Poetics, politics, aesthetics, poiesis, politeia, solitude, community 
La relación entre poética y política, hoy día, se ve fracturada por un mundo a su vez fracturado, en crisis. Esta incomunicación entre lo poético y lo político se desplaza a menudo, de una forma sublimada, hacia la relación entre estética y ética. Pero lo más frecuente es que poiesis y politeia estén aprendiendo a subsistir en una soledad que las condena a la esterilidad. En los límites inseguros de una subjetividad perforada por nuevas formas de autoritarismo, depresión económica y desequilibrio social, una primera pregunta podría ser: ¿qué opciones quedan para que la creatividad se convierta en una nueva forma de comunicación, de vínculo crítico? Y, en este sentido, ¿̇se puede responder a esta pregunta sin antes reconsiderar atentamente los condicionantes de la relación entre poética y política, entre soledad y comunidad?

De entrada, estas interrogaciones iniciales recuerdan el diálogo que se establece entre dos personajes (un aspirante a escritor y un ex-nazi) durante la parte final del film Falso movimiento (Falsche Bewegung) de Wim Wenders (1975). El primero afirma en tono desiderativo: "-Ojalá lo político y lo poético pudieran ser una misma cosa." A lo que el segundo responde con frialdad: "- Sería el final de la nostalgia. Y el fin del mundo." Dejando aparte la tentación apocalíptica, este fragmento de diálogo sigue siendo significativo. Actualmente se extiende una experiencia de expropiación o sustracción, de pérdida de mundo, que se deriva de múltiples factores pero, especialmente, de cómo la crisis económica influye en lo más profundo del "sentir de la gente" (Stiglitz 2015: I). De hecho, se estima que el crack económico y político datable en torno a 2010 ha llevado a escala global un nuevo episodio de Gran Recesión que reproduce los contextos de colapso acontecidos previamente en las décadas de 1930 y 1970 (Stiglitz 2015; 2010).

\section{¿Crisis estética o poética crítica?}

La crisis económica y sociopolítica es además una crisis de las formas heredadas de entender el mundo, es decir, una ocasión para la crítica epistemológica y la creatividad conceptual. Por supuesto, el pantanoso y magnético terreno del arte experimenta también su crisis mundana de una manera que no puede desligarse de la crisis general y vital del momento: cualquier forma de crisis particular participa como reflejo y también como interferencia activa en la crisis general. En este sentido, "la apuesta, aquí, no solamente 
atañe a las cosas del arte, sino a las maneras por las cuales hoy nuestro mundo se dispone a discernir y los poderes afirman su legitimidad" (Rancière 2012: 26). Desde esta perspectiva, Jacques Rancière ha planteado la cuestión del malestar en la estética como una oportunidad histórica para la crítica de los regímenes de la sensibilidad así como de los dispositivos de pensamiento que nos hacen pensar este sensorium de maneras específicas. La crisis de la estética implica a su vez una crisis de la poética como modo práctico y creativo de concebir lo político. Pero son justamente estas implicaciones las que habría que clarificar para poder avanzar de forma crítica por esta vía.

Para Rancière, las transformaciones del arte a lo largo del siglo veinte tienen que ver con la crisis del paradigma mimético como orden representativo que "ajustaba las reglas del arte a las leyes de la sensibilidad y las emociones de éstas a las perfecciones del arte" (2012: 22). Más al fondo, la erosión de la figuración mimética implicaría el desgaste de la legislación que armonizaba la poética y la estética, lo que contribuiría a la reapertura crítica de la relación entre poiesis y aisthesis como mecanismo de orden filosófico y político. De esta desestabilización se habría seguido, en fin, un énfasis en la estética que desembocaría en la oscilación entre las concepciones no-éticas e hiper-éticas propias del arte post-utópico contemporáneo. Según como Rancière considera la concepción estética moderna,

Las bellas artes son tales porque las leyes de la mimesis definen en ellas una relación reglamentada
entre una forma de hacer -una poiesis- y una forma de ser -una aisthesis- que se ve afectada por ella.
Esta relación de a tres, cuyo garante se llama "naturaleza humana", define un régimen de
identificación de las artes que he propuesto designar "régimen representativo". El momento en que el
arte sustituye con su singular al plural de las bellas artes y evoca, para pensarlo, un discurso que se
llamará "estético", es el momento en el que se deshace ese nudo de una naturaleza productiva, de
una naturaleza sensible y de una naturaleza legisladora que se llamaba mimesis o representación. (2012: 16)

Al mismo tiempo, la realidad o "naturaleza" que armonizaba las obras individuales con las sensibilidades sociales regulaba además las formas de otorgar estatus simbólico y colocaba al artista en un lugar propio, separado y privilegiado en la sociedad (2012: 23). De ahí se habría seguido un efecto de elitismo del arte que, así las cosas, no procede 
intrínsecamente de la práctica artística sino más bien de la forma en que el fenómeno artístico era regulado y socializado en tanto fenómeno mimético y propiamente estético.

La institucionalización del arte durante la modernidad europea en los siglos XVIII-XIX, como se sabe, implicaría la activación de dispositivos ideológicos y pragmáticos de distinción y exclusión social. Desmantelar dichos dispositivos, siguiendo la argumentación de Pierre Bourdieu, conlleva necesariamente una "renuncia al angelismo del interés puro por la forma pura" (1995: 15), es decir, una puesta en diálogo de las condiciones internas y supuestamente externas al circuito artístico. Este cuestionamiento dialógico debería ser capaz de poner en crisis el falso movimiento heredado por pre-conceptos y pre-juicios que obturan la comprensión de las relaciones entre política y poética. Siguiendo a Bourdieu, la soledad es a la vez la primera condición y la primera consecuencia de este gesto crítico:

El cuestionamiento de las formas de pensamiento vigentes que efectúa la revolución simbólica y la originalidad absoluta de lo que engendra tienen como contrapartida la soledad absoluta que implica la transgresión de los límites de lo pensable. (1995: 151-152)

Aunque resulten en exceso enfáticos términos como "revolución" o incluso "originalidad" se puede deducir de aquí, en efecto, que la crítica simbólica que implica en gran medida buena parte del arte contemporáneo podría estar quedando neutralizada por la posición de soledad que socialmente ocupa. Por su parte, esta soledad no puede separarse de la concepción ilusionista o "angelista" que el propio arte legitima, desde luego, pero que también se ve respaldada por la subsunción de la práctica artística (entendida como práctica poética, creativa) dentro del régimen (desde Kant, supuestamente desinteresado) de lo estético. La referencia al campo del poder se vuelve así inevitable de cara a entender cómo cada campo de lo estético, artístico o poético produce una forma específica de illusio que cumple una función estratégica para la lógica del campo pero que, al mismo tiempo, tiende a ocultar justamente el problema del poder, de hasta qué punto "la verdad es un envite de luchas" (Bourdieu 1995: 436).

Observando en conjunto el siglo XX, del teatro de Bertolt Brecht a las fotografías de Rineke Dijkstra o las videoinstalaciones de Bill Viola, pasando por el cine de Jean-Luc Godard, entre otros casos sintomáticos, Rancière incide en cómo 
el arte no es político, en primer lugar, por los mensajes y los sentimientos que transmite acerca del orden del mundo. No es político, tampoco, por la manera en que representa las estructuras de la sociedad, los conflictos o las identidades de los grupos sociales. Es político por la misma distancia que toma con respecto a sus funciones, por la clase de tiempo y de espacio que instituye, por la manera en que recorta este tiempo y puebla este espacio. (2012: 33)

El arte es político por el modo en que se vincula a la vida en común, y este vínculo se debilita tanto por el recurso museístico (que pretende un espacio absolutamente fuera de lo cotidiano) como por el recurso participativo o relacional (que busca un lugar para el arte absolutamente interior con respecto a la vida pública diaria). Pero la raíz política del arte, de lo poético, subsistiría respirando todavía en la imposibilidad de sostener ninguna espacialidad ni absolutamente exterior (o sociológica) ni absolutamente interior (o estética). Esta imposibilidad es a la vez pre-condición de un entre o in-between comunicativo que articule de un modo otro, sin identidad, un diálogo productivo (y no meramente reproductivo) donde soledad y comunidad se escuchen mutuamente.

Rancière ve necesario aclarar que "la política consiste en reconfigurar el reparto de lo sensible que define lo común de la comunidad [...]. Este trabajo de creación de disensos constituye una estética de la política" (2012: 35). En este punto Rancière realiza dos gestos entrecruzados: por una parte, conecta lo artístico con la práctica del disenso contra la dominación y relaciona esta crítica con cómo "la libertad del juego se opone a la servidumbre del trabajo" (2012: 42). Mallarmé, Schiller o Rimbaud ilustrarían hasta qué punto un juego de lenguaje, o huelga o acción libre, pueden suponer refutaciones prácticas de la dominación política. Por otra parte, en Rancière, la relación entre arte y política se sigue formulando en clave estética, como "una estética de la política" (o política estética) que sigue hablando en nombre del momento poético que había quedado reactivado por la crisis del paradigma mimético -pero que parece desalojado por esta insistencia filosófica en el campo estético.

El vínculo entre poiesis y aisthesis es tan crucial como su diferencia, que Rancière subraya reconociendo a este último término (lo estético) la condición ontológica de los "modos de ser" y al primero (lo poético) la condición pragmática de los "modos de hacer". Sin embargo, la reivindicación que hace Rancière de una crítica de la estética le hace 
focalizar esa misma dimensión estética a la vez que relegar a un segundo plano la cuestión poética. De ahí que se le pueda objetar, como ha hecho Henri Meschonnic, que este énfasis en lo estético implica una ceguera o sordera ante la práctica poética, y que "este control de los filosofismos sobre la poesía es intolerable" (2007: 62). La zona de la poética podría aquí equipararse al ámbito común de la creatividad lingüística, simbólica, pero su integración en el código de la estética hace que lo poético quede emplazado no tanto al nivel de lo político sino bajo la supervisión o el control de la filosofía (por muy política que esta filosofía pretenda ser). Si, por una parte, la argumentación de Rancière supone un avance en la crítica actualizada de la dimensión estética también, por otra parte, podría entonces pensarse que su enfoque desatiende el papel de la función poética en este orden de cosas.

En efecto, como Rancière afirma, "arte y política se encuentran ligados a pesar de sí mismos, como formas de presencia de cuerpos singulares en un espacio y un tiempo específico" (2012: 36), esto es, son mutuamente dependientes de la misma forma que lo son la autonomía y la politización. Claro que arte y política comportan dos realidades que "deben ser puestas en relación", pero la forma de esta relación se juega de manera distinta (por no decir contraria) si se antepone la dimensión poética (pragmática y política) a la dimensión estética (ontológica y filosófica) del problema, o si sucede al revés, como de hecho sucede en los debates al uso. En otras palabras, si no se tiene esta precaución en cuenta, se corre el riesgo de que, tras una voluntad crítica supuestamente radical, el paso tan metafísico como autoritario de Platón siga reproduciéndose de forma tan imperceptible como eficaz. En tanto “la política misma resulta excluida por el gesto platónico" (Rancière 2012: 36) ¿en qué medida excluiría la política un supuesto primado de la estética sobre la poética?

\section{La poética en la práctica}

Ya Ludwig Wittgenstein en sus Investigaciones filosóficas (original de 1952) apreciaba que hay que enfrentarse a "problemas filosóficos cuando el lenguaje se va de vacaciones" $(I F, 38)$, a la vez que defendía analíticamente que un juego de lenguaje va unido a una forma de vida $(I F, 23)$. Pues bien, la fórmula de un-lenguaje-que-se-va-de-vacaciones no está muy lejos de la reivindicación de la dimensión libertaria, no necesariamente reproductiva ni instrumental, que pone en juego la función poética (Jakobson 1985). Si ya la politeia griega 
era una apelación a la convivencia y las formas distintas de estar juntos, entonces la política puede ser entendida como el arte de la reunión. Lo político interactúa así con el distanciamiento y la rearticulación del tiempo-espacio que hace posible la poiesis. Como sístole y diástole, política y poética se necesitan recíprocamente sin confundirse en una unidad ni totalidad ideal -por mucho que esta confusión neutralizaría angustias y conflictos muy frecuentes. Poética y política se buscan en la medida en que ambas comparten su mutua pertenencia a las exigencias de la praxis, es decir, cuando tienen en común la urgencia de formar y transformar el mundo común. De esa búsqueda dependería que la función poética, por decirlo así, funcione realmente como "función polémica" (Rancière 2012: 67).

Es como si el giro ético en boga a comienzos del siglo XXI debiera contrastarse con un giro práctico que quizá siga todavía pendiente en la filosofía política. Este giro práctico, por paradójico que parezca, debería asumir la soledad como punto de partida, en la medida en que ya "la soledad de la obra lleva consigo una promesa de emancipación" (Rancière 2012: 49). La soledad interviene así como una especie no de horizonte pero sí de exigencia: exigencia de asunción de los límites de un mundo impuesto, que se realiza institucional y cotidianamente como tal. Por lo demás, no puede obviarse el aviso de Gramsci: "En principio, una filosofía de la praxis sólo puede presentarse con una actitud polémica y crítica" (2011: 54). Parece claro que, como indica Rancière, "la política consiste en reconfigurar el reparto de lo sensible que define lo común de la comunidad" (2012: 35). La cuestión, sin embargo, tiene aquí que ver con si "lo sensible" ocupa solamente la posición de objeto (cuyo sujeto sería por ejemplo el saber filosófico o estético) o también de sujeto. Lo sensible-sujeto, así considerado, podría entonces actuar a modo de proyector de una “energía transferible" (Eidsheim 2015: 16) que no fuera políticamente inofensiva.

En condiciones de desfondamiento de las condiciones de vida existentes esta crítica, en fin, no puede no ser autocrítica si su horizonte es refundar nuevas comunidades políticas en condiciones de precariedad extrema. La vida precaria, al contrario de lo que se pretende que sea fácil creer, no aleja sino que vuelve inminente la cuestión de la alteridad, en tanto comienza por preguntarse: “¿Qué soy sin ti? Cuando perdemos algunos de estos lazos que nos constituyen no sabemos quiénes somos ni qué hacer" (Butler 2006: 48). En otras 
palabras, la precariedad afecta tan radicalmente a los modos de ser como a los modos de hacer, y tal vez conlleve repensar en común cuáles de estos modos han de priorizarse o si fuera viable entender la comunidad sin jerarquías entre unos y otros. Puede que así, como alguna vez ha apuntado la poeta Adrienne Rich, la experiencia artística ayude, aún mejor que hasta hoy, a "elaborar nuestra capacidad de conectar con otras gentes asediadas, sufrientes, privadas de privilegios" (2005: 88) que han tenido que hacer de la precariedad una resistente, nueva y entera forma de vida.

La hipótesis que aquí se plantea es que, en la filosofía moderna, poética y estética se hayan confundido supeditando la primera a la segunda. Esta supeditación, a su vez, podría estar bloqueando la dimensión política y crítica y de la poética. De ahí la necesidad de clarificar la diferencia entre poética y estética.

Volviendo a Rancière, puede reconocerse con cierta claridad aquí una diferencia y a la vez relación (una diferencia en relación) entre dos elementos. De una parte, en lo que se refiere a la poética, un elemento de poiesis entendida como "forma de hacer" (Rancière 2012: 16), como práctica creativa que se realiza de modos específicos (verbales, visuales, sonoros, espaciales...) mediante cada arte o técnica (tecné). De otra parte, en cuanto a la estética, un elemento de aisthesis definida como "forma de ser" (2012: 16), como mecanismo de reconocimiento o identificación que engloba todas esas artes o modos poéticos de creatividad situándolos como tales (en contraste con otras prácticas y/o discursos sociales de tipo jurídico, científico, éticos...). La estética establecería así una relación con la poética que permitiría a ésta ser pensada y reconocida filosóficamente. La estética activa así "un régimen de identificación de las artes" (2012: 16) mientras la poesía tiende a considerarse como una de esas artes particulares (en concreto, la que trabaja con la materia verbal). Es en este momento cuando se instaura una jerarquía teórica que sobrepone lo estético a lo poético en la medida en que lo primero es condición sine qua non para entender, explicar y regular las actividades y efectos sociales que implica lo segundo.

Pues bien, a la vez que se aprecia aquí "una relación reglamentada" (Rancière 2012: 16) entre estética y política se podría entonces apreciar, al tiempo, que esta relación las desborda a ambas para situarlas en el entramado de las prácticas sociales. Es decir, es una relación que podría considerarse política en un sentido fundamental. En sentido clásico, un 
"régimen representativo" de tipo mimético absorbe políticamente la potencia de la poética en tanto forma de hacer, hacer-dar-forma, trans-formar... es decir, en tanto praxis constitutiva de la dinámica y el cambio sociales. Encapsulada en el reglamento de identificación que funda el pensamiento estético la poética podría así estar viendo limitado el alcance de sus capacidades funcionales (Jakobson 1985) así como de sus efectos sensoriales y corporales, tal como se desprenden de una concepción del sonido como "práctica vibratoria" (Eidsheim 2015: 17). La materialidad funcional y efectiva del sensorium poético verían limitado su margen de maniobra al circular en el interior de un dispositivo filosófico e ideológico, y más concretamente, de carácter tradicionalmente idealizante o metafísico.

La capacidad polémica y crítica de la poética (como creatividad socioartística) se aleja así de su condición de praxis (en el sentido gramsciano, por ejemplo) a la vez que la estética tiende históricamente a institucionalizarse como reglamento de legitimación de lo poético. En consecuencia, en la modernidad tardía puede esperarse una potenciación o empowerment de la estética que tienda a reforzar su legitimidad y autoridad política. Una formulación extrema de este problema se detecta en la era de las vanguardias artísticas y la crisis socioeconómica y política durante el primer tercio del siglo XX. Un célebre documento de este contexto crítico es el "Epílogo" de Walter Benjamin a su ensayo La obra de arte en la época de su reproductibilidad técnica (original de 1936). Benjamin comienza discutiendo la proclama futurista "fiat ars, pereat mundus" ("hágase arte aunque se pierda el mundo") vinculándola al ascenso del fascismo, dado que es el fascismo el régimen político que mejor ilustraría la función de la estética a la hora de sublimar la crisis real y neutralizar respuestas revolucionarias o críticas a esa crisis. "Así sucede con la estetización de la política que propugna el fascismo. $\mathrm{Y}$ el comunismo. $\mathrm{Y}$ el comunismo le responde por medio de la politización del arte" (2012: 85).

Menos citada, por lo demás, es esta otra afirmación de Benjamin al principio de ese mismo "Epílogo": "El fascismo ve su salvación en el permitir que las masas se expresen (en lugar de que exijan sus derechos)" (2012: 83). Esta hipóstasis de la expresión puede estar dándose dentro de una ideología característica del individualismo moderno según la cual la poeticidad se define en última instancia como expresividad. La distinción pragmático- 
lingüística planteada por Jakobson entre función expresiva (centrada en el emisor) y función poética (centrada en el mensaje) se disuelve aquí en favor de una preponderancia de la primera en perjuicio de la segunda, a la vez que los aspectos dialógicos y comunicativos del mensaje-lenguaje se ven desplazados por el poder creciente de los aspectos monológicos e incluso exhibitivos de la función expresiva (que por cierto encuentra un inesperado eco de actualidad en el eslogan publicitario de Facebook: “iExprésate!”).

Esta subsunción moderna de lo poético en lo expresivo podría ser homóloga a la que, desde la filosofía clásica, vendría enmarcando la poética en la estética. El saber y la actividad estética desembocarían así en un "giro ético" (Rancière 2012) que pone el foco en la exposición de mensajes cuyo valor de verdad reside en el lugar del emisor individual. Claro está entonces que "la estética conlleva una política o una metapolítica" (Rancière 2012: 25) y que, más concretamente, esta política puede estar implicando y movilizando los comportamientos generales del individuo-masa.

En este sentido, la preeminencia de la política sobre la poética arrancaría desde la caracterización platónico-aristotélica del logos entendido como saber racional autorizado. No extraña pues el reclamo de la censura sobre la poética defendido por Platón en $L a$ República (en griego Politeia), ni tampoco el cuidado puesto por Aristóteles a la hora de reducir (siguiendo a Platón) la poética a su carácter imitativo o mimético y, simultáneamente, acotar el radio de acción poética a la poesía ya entendida como técnica verbal y representativa determinada. Para Aristóteles la poética adquiere valor en el interior de la tragedia como arte dramático, escénico, y también de la epopeya como "imitación de personas serias" (Aristóteles 2013: 1449b; 46). La poesía en su sentido moderno de arte combinatorio verbal, según Aristóteles, "por el momento sigue sin nombre" (2013: 1447; 36), se convierte en una especie de agujero negro del discurso filosófico.

En cuanto a la música, la apelación aristotélica a la seriedad y la autoridad se observa en su clasificación de los modos musicales en relación con la educación pública de los jóvenes, concluyendo que el modo dorio, siendo el más suave y regular, resulta el idóneo y superior ya que "todos reconocen que es la armonía más firme y que presenta un carácter más varonil" (2013: 1332b; 438-439). Si, además, esta apelación a la masculinidad se da conectada con un ensalzamiento de los señores sobre los esclavos por el expediente de que 
aquellos son libres y éstos no "por naturaleza" (2013: 1255a; 126)... todo parece indicar que la elaboración germinal en Occidente de la relación entre poética y política nace atravesada por condicionantes de poder, de clase y género, que podrían haber pervivido en desarrollos posteriores de dichos conceptos y debates.

La relación entre poética y estética se presenta así como cuestión política de primer orden. A la vez, la neutralización política de la poética en favor de la estética podría contemplarse como un gesto definitorio de una política autoritaria o fascista. La renuncia apolítica al mundo (fiat ars, pereat mundus) encontraría en la estetización de la vida un poderoso mecanismo para esterilizar el desafío específicamente poético de hacer-mundo, dar-forma o trans-formar el mundo de la vida en común. En el violento salto cronológico que va de los siglos V-IV a. C. a los siglos XX-XXI hay, entre otros muchos, un lugar singular para comprender este desarrollo ideológico en los Principios de ciencia nueva de Giovanni Battista Vico, fechados en 1725. La Scienza Nuova de Vico es revisitada y actualizada críticamente, a su vez, en un ensayo de Edward Said incluido en su obra sintomática titulada El mundo, el texto, el crítico (2004). El ensayo en particular de Said se titula "Sobre la repetición":

Para Vico, la repetición es un principio de economía que proporciona a los hechos de su facticidad histórica y a la realidad su sentido existencial. [...] A esta metáfora de engendramiento, cuando se extiende a lo largo de toda la actividad humana, Vico la denominó poética; porque los sujetos son sujetos, dice Vico, porque son productores, y lo que hacen antes que cualquier otra cosa es a sí mismos. Hacer es repetir; repetir es saber debido a que algo se hace. (2004: 158-163)

La dialéctica entre sujeto y mundo aparece aquí, como si dijéramos, enganchada a su vez a la dialéctica entre repetición y función poética. Este enganche admite ser elaborado como un recurso táctico clave para entender el funcionamiento poético musical de las emociones y la comunicación social (Margulis 2014: 14). Así mismo, además, como recuerda Said, la relación entre mundo e (inter)subjetividad depende necesariamente de una cierta dialéctica entre repetición y novedad.

Como señalaría Freud, en un plano psicoanalítico "la novedad será siempre la condición del goce" (2017: 129). Y más en concreto: "en la vida anímica existe una obsesión de repetición que va más allá del principio del placer" (Freud 2017: 113). Desde esta 
perspectiva, el Yo, como depósito y motor libidinal, se proyecta hacia su objeto (des)haciéndose a sí mismo, al tiempo que su deseo traspasa espectralmente la realidad. En el caso de que esa energía del sujeto quede permaneciendo retenida en sí mismo tendríamos entonces que vérnoslas con el narcisismo (Freud 2017: 148). Esta apreciación recuerda directamente el diagnóstico de Colette Soler (2013: 125) a propósito del narcisismo del mundo actual: el narcisismo, tan pujante por cierto en redes digitales como Facebook o Instagram, hace síntoma de una angustia creciente propia de un mundo dañado, en crisis.

¿A qué se debería pues este posible ensimismamiento o encapsulamiento que esteriliza las opciones de unir (creativa y críticamente) lo poético y lo político, incluso el lazo inconsciente pero decisivo entre la soledad y lo común (o la comunidad) (Alemán 2012)? ¿Dónde comienza a producirse esta especie de neurotización autocomplaciente del deseo que esteriliza el goce dentro de una dinámica de incomunicación tan cotidiana como sistémica? ¿Cuál es la causa y el efecto de la tiranía del selfie? Estas preguntas son sintetizadas en el vídeoclip de Moby \& The Void Pacific Choir "Are you lost in the world like me?" (2016): en esta canción la intersubjetividad (you/me) se vive en un régimen de crisis y vértigo al perderse en un mundo también perdido, expropiado o extraviado por la saturación tecnológica, las conductas de masa y la soledad como experiencia común.

\section{Crisis, subjetividad, poeticidad}

Es importante insistir en este punto sobre la dinámica subjetiva para resituar la cuestión de las relaciones entre lo poético y lo político. Señala Freud que "la libido coincidiría con el eros de los poetas y filósofos, que mantienen unido todo lo animado" (2017: 146). Es decir, desde el análisis psíquico, la poesía (y teoría) im-pulsa (y es impulsada por) una necesidad de unión, de re-unión, (se) nutre (de) una necesidad de polis, del mismo modo que la función libidinal consiste así en una "actividad constructiva". Sin embargo, si el espacio de la comunicación (intersubjetivo, social) se satura de "impresiones penosas" (Freud 2016: 184) entonces se impondrá un “impulso defensivo elemental [...] sólo comparable al reflejo de fuga ante los estímulos dolorosos, como una de las principales bases de sustentación de los síntomas histéricos" (2016: 184). Freud elabora en diversos pasajes la reflexión sobre este "dispositivo protector contra las excitaciones" (2017: 118). Se 
ponen así las bases analíticas para entender el acorazamiento de la (inter)subjetividad contra la crisis social (política, económica, cultural). Esta coraza contra el dolor, dado su efecto de parálisis e insensibilidad, de hecho refuerza paradójicamente la crisis común de la que intenta huir, entrando en una inercia auto-represiva que funcionaría a modo de coraza protectora-agresiva.

Siguiendo con Freud, no parece anecdótico que su estudio Más allá del principio del placer (1920) esté fechado justo antes de su conocido ensayo titulado Psicología de las masas (1921). En el primero de estos textos se lee que este dispositivo de acorazamiento se asemeja a la paradoja de una vesícula viviente, lo que

queda constituido por el hecho de que la superficie exterior de la vesícula pierde la estructura propia de lo viviente, se hace hasta cierto punto anorgánica y actúa entonces como una especial envoltura o membrana que detiene las excitaciones, esto es, hace que las energías del mundo exterior no puedan propagarse sino con sólo una mínima parte de su intensidad hasta las vecinas capas que ha conservado su vitalidad. La capa exterior ha protegido con su propia muerte a todas las demás, más profundas, de su análogo destino. [...] Puede intentarse considerar la neurosis traumática común como el resultado de una extensa rotura de la protección contra las excitaciones. (2017: 118-119)

La consecuencia que más inmediatamente se extrae de esto es "el carácter paralizante del dolor" (2017: 123). Este diagnóstico psico-cultural converge de hecho con un poema de Adrienne Rich que dice: "El dolor la convirtió en conservadora. / Allí donde los fósforos tocaron su carne, ostenta una cicatriz" (Rich 1986: 47). En estos versos la crisis subjetiva es enfocada desde el prisma ideológico y físico. Este enfoque (el poemario de Rich, The Will to Change, se publicó en 1971) entronca también con la denuncia simultánea de un nuevo fascismo por parte de Pier Paolo Pasolini, fascismo cuyo ascenso hacia 1970 correría en paralelo a una sociedad que compensa con el consumo compulsivo y el disfrute conformista de los mass-media su tendencia a agudizar la "neurosis general" (Pasolini 2009: 121).

La hipótesis de un dispositivo protector o coraza de carácter la formularía más extensamente Wilhelm Reich en su esfuerzo por articular marxismo y psicoanálisis tal como se aprecia en sus dos ensayos Análisis del carácter (2010) y Psicología de masas del fascismo (2014), ambos publicados por primera vez en una fecha clave como 1933. El argumento 
analítico de Reich no era precisamente amable: el ascenso del fascismo no se debía ni a un accidente histórico ni a una confabulación cortesana, ni a un delirio sin sentido ni a una coyuntura efímera. Precisamente la experiencia de la crisis sistémica y social se habría dado en combinación con experiencias de crisis emocional, corporal y sexual tanto en el plano individual como colectivo. Para Reich, el signo más evidente de esta "peste emocional" y del sufrimiento del sujeto-masa o “individuo-plaga” (2015: 29) es la formación inconsciente de una coraza de carácter cuya función sería suturar o taponar de forma superyoica, y finalmente agresiva, la experiencia de crisis (la crisis de la experiencia) del yo. Por eso en esa coraza caracteriológica "la defensa narcisista encuentra su expresión concreta crónica" (2010: 71). En tono interpelativo declara Reich: “la llegada de Hitler al poder estaba ligada a tu carácter acorazado" (2015: 62).

El esquema analítico reichiano no es tan simple como para postular que la crisis sistémica produce una crisis de la subjetividad, ni tampoco a la inversa. Lo que se plantea es más bien la necesaria interacción entre ambas dimensiones (sistémica y subjetiva, o, como diría poéticamente A. Rich, política y corporal) a la hora de entender tanto los fundamentos de la crisis social como, peor aún, la reacción social hacia un agravamiento de las condiciones opresivas del sistema y una derrota cada vez más dolorosa del deseo de vivir. 0 sea, la reacción de la sociedad hacia una vida social cada vez más dañada, cada vez más invivible $-y$ esto a pesar de la oferta de corazas que va desde las sagas de Batman o Iron Man al bono mensual de electrofitness, pasando por el acondicionamiento del cuerpo a la obsesión por la autoimagen o selfie. No en balde, como indica Susan Sontag: "El arte fascista despliega una estética utópica: la de la perfección física" (2007: 101). Para Sontag, la exaltación fascista de la falta de pensamiento y el rechazo de la labor intelectual vuelve urgente la necesidad de "detectar el anhelo fascista en nuestro medio" (2007: 106).

En la "Introducción" a su manifiesto titulado iEscucha, hombrecillo! (1948) escribía Reich que cada cual "debe percatarse de cómo llega a convertirse en un fascista” (2015: 28). La idea es afilada, polémica, pero... ¿cómo percatarse de procesos fundamentalmente inconscientes? ¿Y cómo cambiarlos cuando son inconscientes debido a que configuran las estructuras sociales e institucionales? Pese al efecto de alarma que el diagnóstico de Reich produce, no deja de ser un reto pendiente considerar la vigencia de ese "pequeño fascista 
de todas las naciones, razas y clases" (2015: 50) que se hospedaría en el modelo contemporáneo de subjetividad. En este sentido, en fin, "la revolución no se afianza porque el portador y guardián de esta revolución, la estructura psíquica de los seres humanos no ha cambiado" (Reich 1993: 172). Es más, como insiste Reich, "la mayor parte de los seres humanos están sometidos al peso de esta coraza: un muro se alza entre ellos y la vida. Éste es el motivo principal de la soledad" (1993: 33).

La soledad interviene aquí, de nuevo, como un lugar crítico: es a la vez refugio donde alimentar el espejismo del confort y la autosuficiencia, pero también es el lugar a la intemperie donde se cruzan las fuerzas transversales de la experiencia colectiva (de masa) con las condiciones singulares de cada subjetividad, de cada cuerpo (aún) vivo como espacio o espaciamiento disponible para el encuentro, para una comunicación de lo no obvio, de lo no común. Solamente en soledad se fragua la necesidad del otro, la ausencia como espectro del amor carnal que nos constituye. Del mismo modo, la persistencia indiferenciada de un otro omnipresente coincide a menudo con una indiferencia no asumida -por ejemplo recurriendo al uso compulsivo del smartphone.

No es extraño, pues, que soledad y común/comunidad se puedan pensar en su mutua pertenencia, en su correspondencia o insuficiencia recíprocas, y que desde ahí se pueda sugerir la posibilidad de una "poética política" (Alemán 2012: 37), sin ideal ni totalidad, pero por eso mismo vivida como táctica inventiva, sin ley. Quizá estas tácticas estén siendo tan biopolíticas, creativas y difusas, como lo es la dinámica global del nuevo capitalismo simbólico o financiero, cuya incidencia económica no radica solamente en su naturaleza económica sino en su capacidad de (des)movilización corporal y cultural.

De ahí que esta (des)movilización, siguiendo a Pasolini (2009), tenga que ver con un "nuevo fascismo", todavía más incisivo que el fascismo clásico en la medida en que habría aprendido a reactivarse mediante el desarrollismo, el consumismo y el magnetismo seductor de los nuevos mass-media como la televisión y la pantallización general de la vida. A su vez, con las transformaciones de la economía política iniciadas en el período 1980-1990, ese "nuevo fascismo" se habría reelaborado desde una clave más económica que política, más corporativa-tecnológica que estatal-militar en lo que podría ser considerado como un fascismo actual de baja intensidad (Méndez Rubio 2017). 
De esta perspectiva, por cierto, no se sigue una mera continuidad de una supuesta esencia fascista intocada e intocable. Más bien se abre la urgencia de considerar cómo las condiciones estructurales que hicieron posible la llegada del fascismo clásico (crisis sistémica en torno a 1930), como el autoritarismo, la propaganda masiva o el racismo, se reinventaron creativamente para reaparecer activas en el contexto del nuevo fascismo (crisis en torno a 1970) hasta, hoy día, reorientar su poder absorbente y destructivo en clave de neoliberalismo financiero globalizado (crisis en torno a 2010).

El carácter cíclico y estructural de estas crisis de acumulación de capital no debería impedirnos reconocer sus diferencias. En su primera fase, el fascismo clásico (1930) concentra su fuerza en el poder de estado basado en el credo nacionalista y de partido único. En un segundo momento, una vez la fase anterior había llegado hasta su summum de logro y de desgaste, un nuevo fascismo (1970) entraría en escena desde una lógica menos partidista que consumista, menos propiamente gubernamental que difusamente desarrollista, menos propagandística que espectacular -en el sentido de cómo el capital se estaría transformando progresivamente en un espectáculo de imágenes (Debord 1998). El escenario generalizado de la guerra y la revolución sería entonces reemplazado por el de la guerrilla y los nuevos movimientos sociales. Pero tanto en estas fases previas como en la más contemporánea (2010) se mantiene un hilo eléctrico, estremecedor, que permanece encendido, y que Reich resumiría argumentando cómo, "bajo las condiciones de un orden social adverso, los individuos más sanos son precisamente los más expuestos a los sufrimientos más intensos" (1993: 35).

El poder de esta realidad establecida consiste en que fuerza a generar corazas que ella misma se encarga de destrozar. Es este exceso de daño el que hace que la subjetividad se enrosque en su propia impotencia, lo que precisamente convierte la subjetividad en conservadora, narcisista o cínica, es decir, en defensora de su verdugo. Es necesario recordar que el efecto más inmediato de la neurosis general o común es el carácter paralizante del dolor. La opresión sistémica entra así en una relación compensatoria con la depresión subjetiva, una relación de doble vínculo que hiperestimula la producción de corazas a la vez que hiperactiva la rotura masiva de cualquier forma de protección. 


\section{Mundo sin poética, política sin mundo}

A modo de conclusión, podría pensarse que un mundo que ha evacuado la dimensión política de la poética es a la vez un mundo acorazado contra la crítica y la creatividad común. Un mundo sin poesía es el lugar crítico donde la poesía aprende a darse como poesía sin mundo (Méndez Rubio 2004). Por la misma razón, un mundo que prescinde del vínculo radical entre poética y política se convierte en un lugar (o no-lugar) donde lo político atraviesa el mundo precisamente como una negación.

La poesía y la poética, entendidas como práctica artística, como formas activas de creatividad social, contrastan con el poder hegemónico asumiendo la forma de un antipoder desplazado, utópico. A propósito del ejercicio de la poesía entre los presos de Guantánamo, se han documentado textos trabajados por la violencia semántica y la rotura sintáctica, así como en testimonios sobre la inquietud que esos poemas despiertan entre los vigilantes. Tomando ese caso de referencia, habla Judith Butler (2017) sobre el "poder galvanizante de lo poético". A propósito de la cuestión fascista, y más en concreto a propósito del juicio al mando nazi Adolf Eichmann en Jerusalén, sugiere Hannah Arendt que aquí "se vio cuán difícil era contar lo ocurrido, cuán difícil era contarlo en términos que no fueran los términos transformadores del lenguaje poético" (2013: 334). Así pues, parece estarse sugiriendo que la función poética conlleva una dimensión crítica de testimonio y orientación en el mundo. $\mathrm{Y}$, al tiempo, se deduce de esta reflexión que es justo esta dimensión política y crítica la que explica por qué lo poético ha sido progresivamente evacuado del sistema educativo, filosófico y cultural.

Contra la obsesión cientificista o empirista, el arte "puede ejercer una influencia indirecta que no se puede medir" (Levertov 2017: 150). De ahí su dificultad para formar parte activa, posible, de la realidad del mundo tal como lo conocemos. Desde esta perspectiva, poetizar lo común, en las condiciones reales del actual capitalismo financiero, debería no limitarse-a pero sí pasar-por atender y entender la soledad como momento crítico: para empezar, asumir su precariedad, su pasaje de rotura, hasta que llegue a abrirse en ella el hueco necesario para un mundo nuevo. El dolor se politiza en la medida en que la relación entre soledad y comunidad asume su fragilidad como parte activa de un mundo demasiado frágil. La soledad no reclama aquí lo común para desaparecer en su interior sino 
para que le haga sitio y quede así trastocado el espacio de la comunicación hacia un sentido más libre y a la vez más vinculante del mundo, hacia una atención a las singularidades que forme parte de la acción compartida.

El argumento que aquí se defiende, en suma, tiene como punto de partida en un primer momento la "inseparabilidad del arte de la aguda crisis social" (Rich 2005: 52). Desde aquí se pueden entender estas palabras de Adrienne Rich: "En tales condiciones, el arte sería aún la voz del hambre, el deseo, el descontento, la pasión, recordándonos que el proyecto democrático nunca termina. Para que esto suceda, ¿qué más tendría que cambiar?" (2005: 53). En un segundo momento, se trata pues de reconsiderar el vínculo entre poesía y mundo, entre poética y política, de modo que puedan comprenderse y activarse más libremente las potencialidades críticas, de cambio social, que radican tanto a un lado como a otro de ese vínculo. Jugando con las palabras, si se habla en términos de una ligazón entre poética y política debería distinguirse entre una unión como ligadura (atadura, esterilidad sin engendramiento), o como ligue (seducción mutua, como si ambas no quedaran sujetas o ligadas-a sino siendo ligadas-la-una-por-la-otra).

Plantear el debate, en fin, en los términos de una seducción recíproca entre poética y política ayudaría tanto a recuperar el vínculo crítico que las une como a cuidar el impulso libertario que las constituye. El poeta sirio Adonis, al estudiar la poesía árabe pre-islámica, declara que en esta poética los amantes no tienen un tiempo o espacio mundanos sino más bien una "tensión de resquebrajamiento" (1997: 23). La poesía yahilí se despliega explorando la libertad de un exilio sin mundo. El desierto se concibe como "un instante que es pura transformación" (1997: 25). La poesía se vive así como primera forma de comunicación y rebelión $(1997: 86,46)$. El desierto del mundo, señala Adonis, "por su viento y su arena, es una forma de espacio-tiempo; se curva e interpenetra, se traslada, confunde y pierde. Es el espacio-pérdida" (1997: 15). El mundo contemporáneo se acoraza y cierra las fisuras que darían lugar a un mundo nuevo. El desafío poético puede aprender ahora de la poesía de la era de la ignorancia (jahiliyyah), actualizar esa extrañeza en un mundo que ignora la dimensión poética por el peligro de cambio y libertad que implica. Esta poética puede ir unida a una política que atraviese, con arena en los ojos, la pérdida del mundo. 


\section{Referencias}

Adonis (1997), Poesía y poética árabes, trad. de Carmen Ruiz Bravo-Villasante, Madrid Ediciones del Oriente y del Mediterráneo.

Alemán, Jorge (2012), Soledad: común. Políticas en Lacan, Madrid, Clave Intelectual.

Arendt, Hannah (2013), Eichmann en Jerusalén, trad. de Miguel Candel, Barcelona, Debolsillo.

Aristóteles (2013), Poética, trad. de Alicia Villar Lecumberri, Madrid, Alianza Editorial.

Benjamin, Walter (2012), "La obra de arte en la era de su reproductibilidad técnica", trad. de Alfredo Brotons, en Obras (Libro I, Vol. 2), Madrid, Abada, 7-85.

Bourdieu, Pierre (1995), Las reglas del arte (Génesis y estructura del campo literario), trad. de Thomas Kauf, Barcelona, Anagrama.

Butler, Judith (2006), Vida precaria (El poder del duelo y la violencia), trad. de Fermín Rodríguez, Buenos Aires, Paidós.

-- (2017), "In some ways, literature and the arts help to make the world bearable", Poet's Country 2, disponible en <https://lithub.com/judith-butler-on-the-poetry-of-guantanamo> (último acceso 11/07/2018).

Debord, Guy (1998), La sociedad del espectáculo, trad. De José Luis Pardo, Valencia, PreTextos.

Eidsheim, Nina Sun (2015), Sensing Sound (Singing \& Listening as Vibrational Practice), Durham/London, Duke University Press.

Freud, Siegmund (2016), Psicopatología de la vida cotidiana, trad. de Luis López-Ballesteros y de Torres, Madrid, Alianza Editorial.

-- (2017), Psicología de masas, trad. de Luis López-Ballesteros y de Torres, Madrid, Alianza Editorial.

Gramsci, Antonio (2011), ¿Qué es la cultura popular?, trad. de Anaclet Pons y Justo Serna, Valencia, PUV. 
Jakobson, Roman (1985), Lingüística y poética, trad. de Joan A. Argente, Madrid, Cátedra.

Levertov, Denise (2017), Pausa versal (Ensayos escogidos), trad. de José Luis Piquero, Madrid/México, Vaso Roto.

Margulis, Elizabeth Hellmuth (2014), On Repeat (How music plays the mind), Oxford, Oxford University Press.

Meschonnic, Henri (2007), La poética como crítica del sentido, trad. de Hugo Savini, Buenos Aires, Mármol Izquierdo.

Méndez Rubio, Antonio (2004), Poesía sin mundo, Mérida: Editora Regional de Extremadura.

-- (2017) iSuban a bordo! Introducción al fascismo de baja intensidad, Madrid, Grupo 5.

Pasolini, Pier Paolo (2009), Escritos corsarios, trad. de Juan Vivanco Gefaell, Madrid, Ediciones del Oriente y del Mediterráneo.

Rancière, Jacques (2012), El malestar en la estética, trad. de M. A. Pettrecca, L. Vogelfang y M. G. Burello, Madrid, Clave Intelectual.

Reich, Wilhelm (1993), La revolución sexual, trad. de Sergio Moratiel, Barcelona, PlanetaAgostini.

-- (2010), Análisis del carácter, trad. de L. Fabricant, Barcelona, Paidós.

-- (2014), Psicología de masas del fascismo, trad. de Alfonso Herrera Salcedo T., Bilbao, DDT Liburuak.

-- (2015), iEscucha, hombrecillo! Discurso sobre la mediocridad, trad. de Juan Jesús Sánchez Pérez, Madrid, La linterna sorda.

Rich, Adrienne (1986), Antología poética 1951-1981, trad. de Myriam Díaz-Diocaretz, Madrid, Visor.

-- (2005), Artes de lo posible (Ensayos y conversaciones), trad. de María Soledad Sánchez Gómez, Madrid, Horas y Horas.

Said, Edward (2004), "Sobre la repetición", en El mundo, el texto y el crítico, trad. de Ricardo García Pérez, Madrid, Debate, 155-173. 
Soler, Colette (2013), Lacan, lo inconsciente reinventado, trad. de Irene Agoff, Buenos Aires, Amorrortu.

Sontag, Susan (2007), Bajo el signo de Saturno, trad. de Juan Utrilla Trejo, Barcelona, Debolsillo.

Stiglitz, Joseph E. (2010), Caída libre (Estados Unidos, el libre mercado y el hundimiento de la economía mundial), trad. de Alejandro Pradera y Núria Petit, Madrid, Taurus.

-- (2015), El precio de la desigualdad, trad. de Alejandro Pradera Sánchez, Barcelona, Debolsillo.

Antonio Méndez Rubio es poeta y ensayista. Profesor Titular en la Universitat de València. Sus libros de poemas fueron recogidos en los ciclos Todo en el aire (2008) y Nada y menos (2015). Se han publicado las antologías Historia del daño (2006), Historia del cielo (2012) y Abriendo grietas (2017). En 2012 Espacio Hudson editó en Argentina Ultimátum (poemas 1991-2011), y en 2013 Vaso Roto publicó en España y México su poemario Va verdad. Entre sus ensayos críticos: Poesía y utopía (1999), La apuesta invisible: cultura, globalización y crítica social (2003), La destrucción de la forma (2008), Comunicación musical y cultura popular (2016), Abierto por obras: ensayos sobre poética y crisis (2016) y el más reciente ¡Suban a bordo! Introducción al fascismo de baja intensidad (2017). Su último libro de poesía es Por nada del mundo (2017). 